\title{
Clinical and Laboratory Characteristics of Children with Autism Spectrum Disorder at Sohag University Hospital
} Abdelrahim Abdrabou Sadek, Amr Ahmed Osman, Marina Naseralla Samy*

Department of Pediatrics, Faculty of Medicine, Sohag University, Sohag, Egypt

*Corresponding author: Marina Naseralla Samy, Mobile: (+20) 01069411092, E-Mail: marinaatef_2020@yahoo.com

\begin{abstract}
Background: Autism Spectrum Disorder (ASD), sometimes referred to as "autism", is "a chronic disorder whose symptoms include failure to develop normal social relations with other people, impaired development of communicative ability, lack of imaginative ability, and repetitive, stereotyped movements".

Objective: To assess the clinical and laboratory characteristics as well as risk factors of ASD.

Patients and methods: The study was a retrospective descriptive cohort study and included 1650 autistic patients with AD/ASD referred to the Pediatric Department and Psychiatry Outpatient Clinic at Sohag University Hospital, Egypt, and followed up during the period from June 2019 to May 2020.

Results: Age at presentation ranged from one month to 252 months with a mean \pm SD of $44.496 \pm 28.435$. The results of IQ of the studied patients were available in 241 patients with a range from 25 to 100 with a mean IQ of 62.98. Our CARS data were available in 920 of the studied patients $(n=920)$ and showed a mean of 30.064 with a range from 20 to 60. In our study, the associated risk factors of autism were reported in 332 patients. Hearing problems were found in $25.9 \%$, neonatal asphyxia in $15.9 \%$, phenylketonuria was found in $11.8 \%$ of those patients. Epilepsy was found in $7.8 \%$, hyperammonemia in $5.3 \%$, cerebral malformation in 5.1\%, down syndrome in 3.3\%, and tuberous sclerosis in $2.8 \%$.

Conclusion: Our study confirmed diagnosis of ASD in children affects patients, family, and the community at large. Knowledge of ASD is crucial for health professionals as its prevalence is increasing globally.

Keywords: Clinical and laboratory characteristic, Autism Spectrum Disorder-
\end{abstract}

\section{INTRODUCTION}

Autism Spectrum Disorder (ASD), sometimes referred to as "autism", is a chronic disorder whose symptoms include failure to develop normal social relations with other people, impaired development of communicative ability, lack of imaginative ability, and repetitive, stereotyped movements" ${ }^{(1)}$.

Individuals with autism disorder have markedly different social and emotional actions and reactions than non-autistic individuals. For example, many autistic children do not seem to care whether or not they get attention from their parents. ASD also affects IQ. While $30 \%$ of individuals with autism have an average or gifted IQ, 70\% are considered mentally retarded ${ }^{(2)}$.

For an individual to be diagnosed with ASD, he or she must be several qualifications as stated in the Diagnostic and Statistical Manual of Mental Disorders (DSM-V). These include a qualitative impairment in social interaction and communication, restricted repetitive and stereotyped patterns of behaviors, interests, and activities, and delays in functioning. Diagnosis also requires that Rett's Disorder and Childhood Disintegrative Disorder - which have similar symptoms - do not better account for the behaviors ${ }^{(3)}$.

There is no single cause of autism. Genetic factor, In the last five years, scientists have identified a series of rare genetic changes or mutations associated with autism. They have already identified over 100 genes connected to the risk of autism. However, there is not just one mutation in the majority of cases but rather a complex and variable combination of environmental and genetic risk factors that influence early brain development ${ }^{(3)}$.
The most significant risk factor is having one or more relatives with ASD. Hence the risk of having a second child with ASD is around 2-6\%. And this possibility increases even further up to $50 \%$ if more than one sibling is already affected by ASD. In the case of identical (monozygotic) twins who share the same genetic material, there is a $60 \%$ possibility that they would both have ASD, but this increases to $90 \%$ in the presence of a significantly impaired capacity for social interaction ${ }^{(4)}$.

Environmental factors may play a role before and during childbirth.

Those with the greatest evidence of an increased risk of autism are, Advanced age of parents at the time of conception (both the mother and the father), illnesses suffered by the mother during pregnancy that trigger important immune responses, Extreme prematurity, with very low birth weight, complications during childbirth, particularly any that involve a reduction in the oxygen supply reaching the baby's brain, Treatment for epilepsy (treatment with valproic acid during pregnancy), Exposure to high levels of pesticides or air pollution in pregnant women ${ }^{(5)}$.

Among the environmental factors, vaccines have been ruled out as a risk factor for autism. It is important to remember that these factors alone do not cause autism. Only when they are combined with genetic risk factors may they produce a modest increase in risk. Although the causes of autism are complex and have yet to be fully elucidated, there is no doubt whatsoever that it is not caused by bad parenting and the medical community considers it to be a biological disorder ${ }^{(5)}$. 
One of the most widely-used forms of behavior therapy for individuals with ASD is Applied Behavior Analysis (ABA). Behavior analysis grew to prominence in the field of psychology from the work of B. F. Skinner in the $1930 \mathrm{~s}^{(\boldsymbol{6})}$.

ABA has shown itself to be very helpful in teaching individuals with ASD "learn specific skills, such as how to communicate, develop relationships, play, care for themselves, learn in school, succeed at work, and participate fully and productively in family and community activities, regardless of their age" (6).

Because of its high effectiveness, ABA has helped individuals with ASD to function both personally and in society and it remains one of the most popular and well-researched forms of therapy for ASD.

The role of medication in ASD treatment has largely been to improve the effectiveness of behavior therapy. Individuals with ASD may be deficient in certain vitamins and minerals. Two of the most commonly taken supplements for ASD individuals are magnesium and Vitamin B. Specific diets may also be implemented to improve the wellbeing of the individual (7).

The present study aimed to assess the clinical, laboratory characteristics, and risk factors of ASD.

\section{PATIENTS AND METHODS}

The study was a retrospective descriptive cohort study and included 1650 autistic patients with AD/ASD referred to the Pediatric Department and Psychiatry Outpatient Clinic at Sohag University Hospital, Egypt, and followed up at Psychiatry Unit in Sohag University Hospital, Egypt in the period from June 2019 to May 2020. Patients met the diagnostic criteria of autism as defined in the International Classification of Diseases, 10th edition (ICD-10). Their ages ranged from one month to 252 months.

\section{Diagnostic Criteria for Childhood Autism (ICD- 10):}

According to the International Classification of Diseases (ICD-10) issued by WHO ${ }^{(8)}$ :

(A) Abnormal or impaired development is evident before the age of 3 years. (B) Qualitative abnormalities in reciprocal social interaction. (C) Qualitative abnormalities in communication. (D) Restricted, repetitive, and stereotyped patterns of behavior, interests, and activities.

\section{Inclusion criteria:}

Patients who met the diagnostic criteria of autism as defined in International Classification of Diseases, 10th edition (ICD-10) and diagnosed based on Diagnostic and Statistical Manual of Mental Disorder 5th edition (DSM 5) classification, and both sexes.

Exclusion criteria: Any co-morbid psychiatric disease, any chronic illness, and severe hearing loss.
All patients' files were evaluated and the following data were extracted:

1- Detailed history taking: Socio-demographic factors, especially age, gender, and residence, present history of the disease, family history, especially history of neurological problems, careful recording of any allergic manifestations, careful recording GIT disturbance, developmental history, and associated factors as epilepsy and chromosomal or genetics disorders.

2- Pedigree construction up to three generations: With particular emphasis on consanguinity, and family history of similarly affected members or autoimmune disease.

3- Comprehensive clinical examination: Full clinical examination (general, systematic, and detailed neurological examinations), including developmental assessment, was done.

4- Main anthropometric measurements: Including head circumference according to the WHO curves.

5- Investigations: Routine investigations were done for the patients (if available): EEG, CT and MRI brain, metabolic screening, hearing test and MRI or $\mathrm{CT}$, and karyotyping.

\section{6- Intelligent Quotient (IQ) assessment:}

Intelligent Quotient (IQ) assessment was done using Stanford- Binet Intelligence Scales V, as it can be used to children and assessing both verbal and nonverbal domains. The test publisher classification was set as: $145-160$ (very gifted or highly advanced), 130-144 (grifted or very advanced), 120-129 (superior), 110-119 (high average), 90-109 (average), 80-89 (low average), 70-79 (borderline impaired or delayed), 55-69 (mildly impaired or delayed) and 40-54 (moderately impaired or delayed) ${ }^{(9)}$.

7- Rating the severity of autism using Childhood Autism Rating Scale (CARS):

The C.A.R.S is used for the assessment of the severity of autistic features. It consists of 15 categories; each rated on a 4-point scale (may be extended to 7 points by the insertion of intermediate points). The child may be rated between two descriptions by using ratings $1.5,2.5$, or 3.5 . The 15 categories include: relating to people, imitation, emotional response, body use, object use, adaptation to change, visual response, listening response, taste, smell, and touch response and use, fear or nervousness, verbal communication, non-verbal communication, activity level and consistency of intellectual response, and general impressions, scoring of patients were considered as the following: The individual is considered non-autistic when his total score fall in the range of 15-29, mildly-moderately autistic when his total score fall in the range of 30-37, and severely autistic when his total score fall in the range of 38-60 ${ }^{(\mathbf{1 0})}$.

Ethical consent:

Approval of the study was obtained from Sohag University academic and ethical committee. Every 
patient signed informed written consent for the acceptance of the operation.

This work has been carried out following The Code of Ethics of the World Medical Association (Declaration of Helsinki) for studies involving humans.

\section{Statistical analysis}

Clinical and laboratory data were collected and through Excel 2015 for Windows and analyzed using SPSS 16.00 software. Categorical data expressed as percentages and continuous data as mean and standard deviation, in case of normally distributed data, and median and interquartile range, in case of abnormally distributed data.

\section{RESULTS}

Males represented $75.3 \%$ of the studied patients. Age at presentation ranged from 1month to 252 months with a mean $( \pm$ SD) of $44.496( \pm 28.435)$

The data of birth order was available in $97.6 \%$ of the studied patients (1610 patients). Of them, $42 \%$ were the first, $24.8 \%$ were the second. Third, fourth, and fifth-order were recorded in $14.3 \%, 9.6 \%$, and $5.3 \%$ of patients respectively. About $2.5 \%$ had their order ranged from $7^{\text {th }}$ to $12^{\text {th }}$ in their family. Consanguinity data was available in $65.5 \%$ of patients $(n=1080)$. Out of them, $43.6 \%$ had positive consanguinity. Data about family history was available in $59.5 \%$ of patients $(n=981)$. Positive family history was reported in $16.5 \%$ of them.

Regarding presenting complaints, a larger percentage of patients presented with DLD (82.1\%) followed by hyperactivity/poor attention (57.3\%), GDD $(12.1 \%)$, stereotyping $(8.8 \%)$, and social isolation (6.6\%). Convulsions and delayed motor development were the presenting complaints in $3.2 \%$ and $0.4 \%$ of the studied patients respectively. About $69.6 \%$ presented with multiple complaints while $30.4 \%$ had only a single complaint on presentation.

Regarding neurological examination, data were available in 1614 patients. Out of them, $88.7 \%$ had normal examination, and $9.1 \%$ had hypotonia.

The results of IQ of the studied patients were available in 241 patients with a range from 25 to 100 with a mean IQ of 62.98 while CARS data was available in 920 of the studied patients $(n=920)$ and showed a mean of 30.064 with a range from 20 to 60 (Table 1).
Table (1): Distribution of the studied patients according to demographic data, birth order, complaint, neurological examination IQ, and CARS

\begin{tabular}{|c|c|c|}
\hline & $\mathrm{N}=1650$ & $\%$ \\
\hline $\begin{array}{l}\text { Gender: } \\
\text { Females } \\
\text { Males }\end{array}$ & $\begin{array}{c}407 \\
1243\end{array}$ & $\begin{array}{l}24.7 \% \\
75.3 \%\end{array}$ \\
\hline $\begin{array}{l}\text { Age at presentation: } \\
\text { Mean } \pm S D \\
\text { Range }\end{array}$ & \multicolumn{2}{|c|}{$\begin{array}{c}44.496 \pm 28.435 \\
1-252\end{array}$} \\
\hline & $\mathbf{N}$ & $\%$ \\
\hline $\begin{array}{l}\text { Birth order: } \\
1^{\text {st }} \\
2^{\text {nd }} \\
3^{\text {rd }} \\
4^{\text {th }} \\
5^{\text {th }} \\
6^{\text {th }} \\
7^{\text {th }}-12^{\text {th }}\end{array}$ & $\begin{array}{c}\mathbf{N}=\mathbf{1 6 1 0} \\
677 \\
400 \\
231 \\
155 \\
85 \\
32 \\
40\end{array}$ & $\begin{array}{c}42 \% \\
24.8 \% \\
14.3 \% \\
9.6 \% \\
5.3 \% \\
2 \% \\
2.5 \%\end{array}$ \\
\hline $\begin{array}{l}\text { Consanguinity: } \\
\text { No } \\
\text { Yes }\end{array}$ & $\begin{array}{c}\mathbf{N}=\mathbf{1 0 8 0} \\
609 \\
471\end{array}$ & $\begin{array}{l}56.4 \% \\
43.6 \%\end{array}$ \\
\hline $\begin{array}{l}\text { Family history: } \\
\text { No } \\
\text { Yes }\end{array}$ & $\begin{array}{c}\mathbf{N}=\mathbf{9 8 1} \\
819 \\
162\end{array}$ & $\begin{array}{l}83.5 \% \\
16.5 \%\end{array}$ \\
\hline Complaint: & $\mathrm{N}=1650$ & $\%$ \\
\hline $\begin{array}{l}\text { DLD } \\
\text { Hyperactivity/poor } \\
\text { attention } \\
\text { GDD } \\
\text { Stereotyping } \\
\text { Social isolation } \\
\text { Convulsions } \\
\text { Delayed motor } \\
\text { development }\end{array}$ & $\begin{array}{c}1354 \\
946 \\
199 \\
145 \\
109 \\
52 \\
7\end{array}$ & $\begin{array}{c}82.1 \% \\
57.3 \% \\
12.1 \% \\
8.8 \% \\
6.6 \% \\
3.2 \% \\
0.4 \%\end{array}$ \\
\hline $\begin{array}{l}\text { Single } \\
\text { Multiple }\end{array}$ & $\begin{array}{c}501 \\
1149 \\
\end{array}$ & $\begin{array}{l}30.4 \% \\
69.6 \% \\
\end{array}$ \\
\hline $\begin{array}{l}\text { Neurological } \\
\text { examination: }\end{array}$ & $\mathrm{N}=1614$ & $\%$ \\
\hline $\begin{array}{l}\text { Normal } \\
\text { Hypotonia } \\
\text { Hypertonia }\end{array}$ & $\begin{array}{c}1432 \\
147 \\
35\end{array}$ & $\begin{array}{l}88.7 \% \\
9.1 \% \\
2.2 \%\end{array}$ \\
\hline Hypertonia & \multicolumn{2}{|c|}{$\mathrm{N}=1650$} \\
\hline $\begin{array}{l}\text { IQ: } \\
\text { Mean } \pm \text { SD }\end{array}$ & \multicolumn{2}{|c|}{$\begin{array}{c}\mathbf{N}=\mathbf{2 4 1} \\
62.98 \pm 11.962\end{array}$} \\
\hline $\begin{array}{l}\text { CARS: } \\
\text { Mean } \pm \text { SD }\end{array}$ & \multicolumn{2}{|c|}{$\begin{array}{c}\mathbf{N}=\mathbf{9 2 0} \\
30.064 \pm 6.134\end{array}$} \\
\hline
\end{tabular}

Data of CT scans were available in 384 patients. About $63.8 \%$ of them had normal CT. Brain atrophy 
was found in $26 \%$ of them. MRI findings were available in 211 patients. Normal MRI was reported in $47.4 \%$ of the patients while $23.2 \%$ of them had brain atrophy.

Data of EEG scans were available in 1268 patients. Out of them, $46.2 \%$, had generalized epileptic discharge, $16.2 \%$ had focal epileptic discharge and $37.6 \%$, had normal EEG.

Audiometry was available in 476 patients. Out of them, $81.9 \%$ had normal hearing. Unilateral OME was detected in $3.4 \%$, while bilateral OME was detected in $0.8 \%$. Unilateral and bilateral hearing loss was found in $2.7 \%$ and $11.1 \%$ respectively (Table 2 ).

Table (2): Distribution of the studied patients according to brain imaging, EEG, audiometry, and the results of karyotyping

\begin{tabular}{|l|c|c|}
\hline \multicolumn{1}{|c|}{ Brain imaging } & $\mathbf{N}$ & $\mathbf{\%}$ \\
\hline CT brain: & $\mathbf{N = 3 8 4}$ & \\
Normal & 245 & $63.8 \%$ \\
Brain atrophy & 100 & $26 \%$ \\
Periventricular calcifications & 9 & $2.3 \%$ \\
WMD & 7 & $1.8 \%$ \\
Dandy-Walker malformation & 7 & $1.8 \%$ \\
Intracranial hemorrhage/HIE & 4 & $0.9 \%$ \\
Dilated ventricles & 4 & $0.9 \%$ \\
Frontal arachnoid cyst & 2 & $0.5 \%$ \\
Bilateral lentiform & 2 & $0.5 \%$ \\
calcification & 2 & $0.5 \%$ \\
ACC & 1 & $0.2 \%$ \\
Chiari malformation & 1 & $0.2 \%$ \\
Bilateral pancystic lesion & & \\
\hline MRI brain: & $\mathbf{N = 2 1 1}$ & \\
Normal & 131 & $47.4 \%$ \\
Brain atrophy & 49 & $23.2 \%$ \\
Miscellaneous & 13 & $6.2 \%$ \\
WMD & 9 & $4.3 \%$ \\
ACC & 3 & $2.2 \%$ \\
Dilated ventricles & 2 & $0.9 \%$ \\
Periventricular leukomalacia & 2 & $0.9 \%$ \\
Chiari malformation & 1 & $0.5 \%$ \\
Dandy walker malformation & 1 & $0.5 \%$ \\
\hline & $\mathbf{N = 1 2 6 8}$ & $\mathbf{\%}$ \\
\hline Generalized epilepsy & $\mathbf{5 8 6}$ & $46.2 \%$ \\
Normal & 476 & $37.6 \%$ \\
Focal epilepsy & $\mathbf{2 0 6}$ & $16.2 \%$ \\
\hline \multicolumn{1}{|c|}{ Audiometry } & $\mathbf{N = 1 6 5 0}$ & $\mathbf{\%}$ \\
\hline & $\mathbf{N = 4 7 6}$ & \\
Normal & 390 & $81.9 \%$ \\
OME & & \\
Unilateral & 16 & $3.4 \%$ \\
Bilateral & 4 & $0.8 \%$ \\
Hearing loss & $\mathbf{N}=\mathbf{5 5}$ & \\
Unilateral & 42 & $76.4 \%$ \\
Bilateral & 11 & $20 \%$ \\
\hline & $1.8 \%$ \\
\hline Normal & 53 & $1.8 \%$ \\
Down syndrome & & \\
Klinefelter syndrome & & \\
Fragile X & & \\
\hline
\end{tabular}

Data of metabolic screen was available in 247 patients. Elevated levels of phenylalanine (PKU) were found in 39 patients $(15.8 \%)$ and elevated ammonia was found in 18 patients $(7.3 \%)$ while 181 patients $(73.3 \%)$ had a normal metabolic screen. Hormonal profile was available in 22 patients; out of them, 21 patients $(95.5 \%)$ had normal hormonal profile (Table 3 ).

Table (3): Distribution of the studied patients according to laboratory analysis

\begin{tabular}{|l|c|c|}
\hline & $\mathbf{N}$ & $\mathbf{\%}$ \\
\hline Metabolic screen: & $\mathbf{N = 2 4 7}$ & \\
Normal & 181 & $73.3 \%$ \\
Elevated phenylalanine & 39 & $15.8 \%$ \\
(PKU) & 18 & $7.3 \%$ \\
Elevated ammonia & 2 & $0.8 \%$ \\
Elevated glycine & 2 & $0.8 \%$ \\
Elevated homocysteine & 2 & $0.8 \%$ \\
Elevated LDH, lactate & 1 & $0.4 \%$ \\
Positive glycosaminoglycan & 1 & $0.4 \%$ \\
in urine (MPS) & $\mathbf{1}$ & $0.4 \%$ \\
Positive ketone bodies & & \\
Elevated creatinine & & \\
phosphokinase & & \\
\hline Hormonal: & $\mathbf{N = 2 2}$ & \\
Normal & 21 & $95.5 \%$ \\
Hyperthyroidism & 1 & $4.5 \%$ \\
\hline
\end{tabular}

The data of perinatal history was available in $56.42 \%$ of the studied patients (931 patients). About, $0.52 \%$ had positive prenatal history. Their mothers had diabetes mellitus and hypertension in $0.1 \%, 0.42 \%$ respectively. About $47.48 \%$ were delivered by NVD and $52.52 \%$ delivered by CS. About $28.46 \%$ of them had a past history of NICU admission. About 18.26\% and 5.69\% were exposed to neonatal jaundice and neonatal asphyxia respectively. Prematurity and LBW were reported in $2.79 \%$ of them (Table 4 ).

Table (4): Distribution of the studied patients according to perinatal history

\begin{tabular}{|l|c|c|}
\hline & $\mathbf{N = 9 3 1}$ & $\mathbf{\%}$ \\
\hline Prenatal history: & $\mathbf{N = 9 3 1}$ & \\
Maternal diabetes & 1 & $0.1 \%$ \\
Maternal & 4 & $0.42 \%$ \\
hypertension & & \\
\hline Natal history: Mode & $\mathbf{N = 9 3 1}$ & \\
of delivery: & 489 & $52.52 \%$ \\
CS & 442 & $47.48 \%$ \\
NVD & 265 & $28.46 \%$ \\
NICU & 170 & $18.26 \%$ \\
Jaundice & 53 & $5.69 \%$ \\
Neonatal asphyxia & 26 & $2.79 \%$ \\
Prematurity & 26 & $2.79 \%$ \\
LBW & & \\
\hline
\end{tabular}

Associated risk factors of autism were reported in 332 patients. About $25.9 \%$ have hearing problems. About $15.9 \%$ were exposed to neonatal asphyxia. Phenyl ketonuria was found in $11.8 \%$ of those patients. 
Prematurity, low birth weight, and epilepsy were reported in $7.8 \%, 7.8 \%$, and $7.8 \%$ of them respectively (Table 5).

Table (5): Distribution of the studied patients according to associated risk factors

\begin{tabular}{|l|c|c|}
\hline Associated risk factors & $\mathbf{N = 3 3 2}$ & $\mathbf{\%}$ \\
\hline Hearing problems & 86 & $25.9 \%$ \\
Neonatal asphyxia & 53 & $15.9 \%$ \\
Phenylketonuria & 39 & $11.8 \%$ \\
Prematurity & 26 & $7.8 \%$ \\
Low birth weight & 26 & $7.8 \%$ \\
Epilepsy & 26 & $7.8 \%$ \\
Hyperammonemia & 18 & $5.4 \%$ \\
Cerebral malformation & 17 & $5.1 \%$ \\
Down syndrome & 11 & $3.3 \%$ \\
Tuberous sclerosis & 9 & $2.8 \%$ \\
White matter disease & 9 & $2.8 \%$ \\
Hyperglycinemia & 2 & $0.6 \%$ \\
Homocystinuria & 2 & $0.6 \%$ \\
Mucopolysaccharidosis & 1 & $0.3 \%$ \\
Ataxia telangiectasia & 1 & $0.3 \%$ \\
Congenital infection & 1 & $0.3 \%$ \\
Corneila de lange & 1 & $0.3 \%$ \\
syndrome & 1 & $0.3 \%$ \\
Sotos syndrome & 1 & $0.3 \%$ \\
Klinefelter syndrome & 1 & $0.3 \%$ \\
Fragile X syndrome & 1 & $0.3 \%$ \\
Hyperthyroidism & & \\
\hline
\end{tabular}

\section{DISCUSSION}

This study shows that males represented $75.3 \%$ of the studied patients. Age at first diagnosis is important as research has shown that early recognition and initiation of early intervention results in an optimal outcome. Age at presentation ranged from one month to 252 months with a mean of $44.5 \pm 28.4$. In a metaanalysis conducted by Loomes $\boldsymbol{e t}$ al. ${ }^{(11)}$, the true maleto-female ratio in children with ASD is found to be closer to 3:1. Elshahawi et al. ${ }^{(12)}$ showed that the male to female ratio of autistic patients was 3.3:1. Kommu et $\boldsymbol{a l} .{ }^{(13)}$ reported a mean of 5.92 years in a study reviewing clinical characteristics of 200 children with ASD.

Ramachandram (14) explored sociodemographic and clinical characteristics of children with Autism Spectrum Disorder (ASD). Of the total of 331 patients, $273(82.5 \%)$ were males and $58(17.5 \%)$ were females. The male to female ratio was $4.7: 1$. The mean age at the first visit to Child Development Clinic (CDC) was 5 years and 6 months (Standard Deviation (SD): 31.68 months) with ages at presentation ranging from 19 months to 18 years and 4 months.

There is a need to look into the severity of ASD and age at diagnosis in further studies as it has been shown that children with less severe ASD symptoms and higher functioning abilities are diagnosed at later ages ${ }^{(15)}$.

Regarding presenting complaints, a larger percentage of patients presented with DLD (82.1\%) followed by hyperactivity/poor attention (57.3\%), GDD
$(12.1 \%)$, stereotyping $(8.8 \%)$, and social isolation (6.6\%). Convulsions and delayed motor development were the presenting complaints in $3.2 \%$ and $0.4 \%$ of the studied patients respectively. About $69.6 \%$ presented with multiple complaints while $30.4 \%$ had only a single complaint on presentation. Regarding neurological examination, data were available in 1614 patients. Out of them, $88.7 \%$ had normal examination, and $9.1 \%$ had hypotonia. Ramachandram (14) reported neurodevelopmental and medical comorbidities.

The results of IQ of the studied patients were available in 241 patients with a range from 25 to 100 with a mean IQ of 62.98 . Sadek et al. ${ }^{(16)}$ showed that the majority of cases $(87 / 77 \%)$ were moderately impaired or delayed, while, $18(18.9 \%)$ cases were mildly impaired or delayed, with the mean overall IQ was $49.08 \pm 10.04$ and ranges between 39 to 97 .

The CARS is based on the clinician's observations of a child's behavior. It is particularly appropriate for the initial screening of autistic symptoms. Our CARS data were available in 920 of the studied patients $(n=920)$ and showed a mean of 30.064 with a range from 20 to 60 .

In our study, data of CT scans were available in 384 patients. About $63.8 \%$ of them had normal CT. Brain atrophy was found in $26 \%$ of them. MRI findings were available in 211 patients. Normal MRI was reported in $47.4 \%$ of the patients while $23.2 \%$ of them had brain atrophy. Sadek et al. ${ }^{(16)}$ found that out of 64 cases who were subjected to brain CT, 39 cases $(61 \%)$ revealed brain atrophic changes. While, 13 cases $(65 \%)$ out of 20 patients with MRI brain, showed white matter disease.

Data of EEG scans were available in 1268 patients. Out of them, $46.2 \%$, had generalized epileptic discharge, $16.2 \%$ had focal epileptic discharge and $37.6 \%$, had normal EEG. Mannion et al. ${ }^{(17)}$ examined the frequency of current comorbid diagnosis, comorbid psychopathology, sleep problems, and gastrointestinal symptoms in children and adolescents with ASD. In their study, $46.1 \%$ of children and adolescents with ASD had a comorbid psychological or medical diagnosis while $10.1 \%$ of them had epilepsy.

Sadek et al. (16) revealed that generalized epileptic discharges were frequent in $24(21.2 \%)$ cases, focal epileptic discharges in $10(8.8 \%)$ cases, hyper arrhythmia pattern in 9(8\%) cases, while, $14(12.4 \%)$ cases have normal ECG. Ramachandram ${ }^{(14)}$ noted history of speech regression was noted in $14.8 \%$ while epilepsy and confirmed genetic disorders were found in $9.4 \%$ and $5.7 \%$ respectively.

Data of metabolic screen was available in 247 patients. An elevated level of phenylalanine (PKU) was found in 39 patients $(15.8 \%)$ and elevated ammonia was found in 18 patients $(7.3 \%)$ while 181 patients $(73.3 \%)$ had a normal metabolic screen. Hormonal profile was available in 22 patients; out of them, 21 patients $(95.5 \%)$ had a normal hormonal profile.

Autism spectrum disorder (ASD) could be the only presentation of untreated PKU and may be 
misdiagnosed among patients who haven't any other features suggesting PKU. The introduction of treatment leads to difficulties in determining the frequency of autistic symptoms in PKU ${ }^{(18)}$. Sadek et al. ${ }^{(16)}$ found that the most frequent presentation was autistic features (27 cases, $23.9 \%$ ).

Our findings were in accordance with the study conducted by Khemir et al. ${ }^{(18)}$ who found that 15 children $(79 \%)$ of their cases had autism. Also, 5.7\% of late-diagnosed PKU children had autism in an Italian study ${ }^{(19)}$.

Fombonne and du Mazaubrun (20) found a significantly higher frequency of untreated PKU patients in the autistic group. Sadek et al. ${ }^{(16)}$ found that more than half of the cases had autism (57 cases, $50.4 \%$ ), with their mean CARS was $30.74 \pm 7.002$.

The variation in the percentages between studies could be attributed to the difference in PKU populations whether early treated, late treated or a mixed group of both.

In our study, data on perinatal history was available in 931 patients. Maternal hypertension and maternal diabetes were two prenatal risk factors for ASD by $(0.42 \%, 0.1 \%)$ respectively. Neonatal jaundice and neonatal asphyxia were the most two natal risk factors $(18.6 \%, 5.69 \%)$ respectively followed by LBW and prematurity $(2.79 \%, 2.79 \%)$.

Maramara et al. ${ }^{(21)}$ found that risk factors found to be greater than $20 \%$ prevalent in their autism spectrum disorders cohort included newborn jaundice (12.6\%), low birth weight (12.3\%), lack of oxygen (6.8\%), hypertension during pregnancy $(5.7 \%)$, gestational diabetes (4.7\%), and other perinatal factors. According to Abd Elhameed et al. ${ }^{(22)}$, the incidence of prenatal, natal, and postnatal complications was higher in the patients who had autism It is suggesting a consistent association of unfavorable events in pregnancy, delivery, and the neonatal phase and autism.

In our study, associated risk factors of autism were reported in 332 patients $20.1 \%$. Hearing problems were found in $25.9 \%$, neonatal asphyxia in $15.9 \%$, and phenylketonuria was found in $11.8 \%$ of those patients. Epilepsy was found in $7.8 \%$, hyperammonemia in $5.4 \%$, cerebral malformation in $5.1 \%$, down syndrome in $3.3 \%$, and tuberous sclerosis in $2.8 \%$. Other studies were consistent with our findings. Billstedt and Gillberg ${ }^{(19)}$ found that none of their patients developed epilepsy after the age of 20 years.

Viscidi et al. ${ }^{(23)}$ compared children with ASD and epilepsy to children with ASD alone on demographic and clinical characteristics and suggested that epilepsy is a common co-morbid condition in individuals with ASD, occurring in approximately $12 \%$ of children with ASD and reaching $26 \%$ by adolescence. They identified several risk factors for epilepsy including older age, low IQ and adaptive functioning, poor language skills, a history of developmental regression, and more severe ASD symptoms. They demonstrated that the most widely reported factors associated with epilepsy are not predictive after adjusting for IQ. Low IQ is the best clinical predictor of epilepsy in children with ASD.

Ramachandram ${ }^{(14)}$ found that fifteen percent of the cohort had medical diagnoses which include common childhood conditions like bronchial asthma and eczema, congenital heart diseases like a ventricular and atrial septal defect, congenital upper airway malformations, and gastro-oesophageal conditions requiring surgery among others.

This study had some limitations which could be addressed in future studies. This sample was obtained from one center with no control group, making the generalization of the results inaccurate.

\section{CONCLUSION}

Our study confirmed diagnosis of ASD in children affects patients, family, and the community at large. Knowledge of ASD is crucial for health professionals as its prevalence is increasing globally. This study reviews the clinical and laboratory characteristics of a cohort of children with ASD. It is hoped that this study can contribute data to encourage a largescale national registry and resource allocation with program planning in the future.

Other additional data which may confer benefit in future studies would include details on age at first parental concern and diagnosis made and follow up of this cohort till secondary school years.

\section{REFERENCES}

1. Carlson $\mathbf{N}$ (2013): Physiology of Behavior (11 ${ }^{\text {th }}$ ed.). United States of America: Pearson Education, Inc; Pp. 594. https://www.pearson.com/us/highereducation/product/Carlson-Physiology-of-Behavior-

11th-Edition/9780205239399.html

2. Sarason I, Saraon B (2005): Abnormal psychology: the problem of maladaptive behavior. Upper Saddle Rivery, New Jersey: Pearson Education, Inc, Pp. 681. https://www.pearson.com/us/higher-

education/program/Sarason-Abnormal-Psychology-TheProblem-of-Maladaptive-Behavior-11thEdition/PGM2819151.html

3. American Psychiatric Association (2000): Diagnostic and statistical manual of mental disorders: DSM-IV [Internet]. 4th ed. Washington (DC), Pp. 866. Available from: http://www.psychiatryonline.com/DSMPDF/dsmiv.pdf

4. Smalley S, Asarnow R, Spence M (1988): Autism and genetics. A decade of research. Arch Gen Psychiatry, 45: 953-61.

5. Jorde L, Hasstedt S, Ritvo E (1991): Complex segregation analysis of autism. Am J Hum Genet., 49: 932-8.

6. Green G, Taylor B, Luce S et al. (2012): Applied behavior analysis. Retrieved from www.autismspeaks.org/what-autism/treatment/appliedbehavioral-analysis-aba, 2012.

7. Mousain-Bosc M, Roche M, Polge A et al. (2006): Improvement of neurobehavioral disorders in children supplemented with magnesium vitamin B6. Magnesium Research, 19(1): 53-62.

8. World Health Organization (1993): The ICD-10 classification of mental and behavioral disorders: 
Diagnostic criteria for research. Geneva: World Health Organization.

https://www.who.int/classifications/icd/en/GRNBOOK.p df

9. Bain S, Allin J (2005): Stanford-Binet Intelligence Scales, fifth edition. Journal of Psychoeducational Assessment, 23: 87-95.

10.Armman E (2007): Childhood Autism Rating Scale (CARS). Autism World, 3:28-32.

11.Loomes R, Hull L, Mandy WP (2017): What Is the Male-to-Female Ratio in Autism Spectrum Disorder? A Systematic Review and Meta-Analysis. J Am Acad Child Adolesc Psychiatry, 56(6): 466-74.

12. Elshahawi H, Shaker N, Essawy H et al. (2007): Risk factors and clinical presentations of autism in an Egyptian sample. Egypt J Neurol Psychiat Neurosurg., 44(1): 6977.

13. Kommu J, Gayathrib K, Srinatha S et al. (2017): Profile of two hundred children with Autism Spectrum Disorder from a tertiary child and adolescent psychiatry center. Asian J Psychiatr., 28: 51-56.

14. Ramachandram S (2019): Clinical characteristics and demographic profile of children with Autism Spectrum Disorder (ASD) at Child Development Clinic (CDC), Penang Hospital, Malaysia. Med J Malaysia, 74(5): 372376.

15. Mannion A, Leader G (2013): Comorbidity in autism spectrum disorder: a literature review. Research in Autism Spectrum Disorders, 7(12): 1595-616.

16. Sadek A, Hassan M, Mohammed N (2017): Clinical and neuropsychological outcome of children with phenylketonuria in Upper Egypt: A single-center five years' experience. Neuropsychiatr Dis Treat., 14:25512561.

17. Mannion A, Leader G, Healy O (2013): An investigation of comorbid psychological disorders, sleep problems, gastrointestinal symptoms and epilepsy in children and adolescents with ASD. Research in Autism Spectrum Disorders, 7: 35-42.

18. Khemir S, Halayem S, Azzouz H (2016): Autism in Phenylketonuria Patients: From Clinical Presentation to Molecular Defects. J Child Neurol., 31(7): 843-9.

19. Billstedt E, Gillberg C (2005): Autism after adolescence: population-based 13- to 22-year follow-up study of 120 individuals with autism diagnosed in childhood. J Autism Dev Disord., 35(3): 351-60.

20. Fombonne E, du Mazaubrun C (1992): Prevalence of infantile autism in four French regions. Social Psychiatric Epidemiol., 27: 203-210.

21. Maramara L, He W, Ming X (2014): Pre- and Perinatal Risk Factors for Autism Spectrum Disorder in a New Jersey Cohort. Journal of Child Neurology, 29(12): 16451651 .

22. Abd Elhameed M, Abd Elbaky A, Kamel E (2011): A Controlled Study of the Risk Factors and Clinical Picture of Children with Autism in an Egyptian Sample. [Egypt J Neurol Psychiat Neurosurg., 48(3): 271-276.

23. Viscidi E, Triche E, Pescosolido M et al. (2013): Clinical Characteristics of Children with Autism Spectrum Disorder and Co-Occurring Epilepsy. PLoS One, 8(7): 67797. 